\title{
Research on Computer-Aided Second Language Learning (CALL) and the Role of Teachers
}

\author{
Zhu Yushuang \\ College of Foreign Languages, Jianghan University \\ Wuhan, China \\ shirley_tony@163.com
}

\begin{abstract}
High technology, especially the use of computers, has won a secure place among the resources available to the modern language teacher because of its prominent advantages. However, despite the great interest shown by their students, many teachers remain uncommitted to computer-assisted language learning, not only because of their lack of computer knowledge themselves, but the integrated disadvantages of computer itself. This article argues that teachers are still needed to drive the computer-aided language learning process and that the teacher's role will not be threatened at all.
\end{abstract}

Keywords-computer aided language learning; autonomy study, medium

\section{INTRODUCTION}

As the development of computer technology, especially after the personal computer is put into mass production, computer is used more and more widely. it penetrates every aspect of human lives from love letters to education, business transactions to personal communication. This article focuses on its use for language learning. CALL is a phenomenon accompanied with the development of computer. Since its birth in 1960s, CALL has experienced three main phases (Kong Wen \& Li Qinghua, 2002): structural CALL, cognitive CALL and social cognitive CALL, and the software in each corresponding phase developed consequently. The ear1y "drill and kill" childhood era has passed, PLATO as one of the representative. In the 1970s, people's focus on language learning shifted from "stimulate-response"theory to comprehensive input. Learners are encouraged to use language to solve problems creatively and to deduce intrinsic rules through hypothesis. As the appearance of Internet and multi-tech, learners' interaction with computer develops into interaction with other humans via computers. People's long-term wish comes true eventually. Since computer can do all that teachers can, what's more, computer has other functions than teachers, such as dynamic models, animation, and variation of colors, which are the basis functions of PowerPoint software. Then what's the use of language teachers? Isn't it the very time for them to retire? This article, however, argues that the effectiveness of CALL depends greatly on teachers and that it may be leading ultimately to autonomy, it cannot yet be regarded as being essentially a self-access operation. It undoubtedly requires more learner training and supervision than other self-access pursuits, and such training and supervision would have to be carried out by teacher.

\section{LITERATURE REVIEW}

As stated above, a new era in CALL has begun. The fast improvement in the technology, that is, the advent of CD-ROM, and especially that of the Internet, has enhanced the creative learning opportunities of the medium. The recognition of CALL as a valid resource appears to have been achieved. However, this encouraging growth has not been accompanied by faith in the wondrous potential of CALL. Keith Cameron insisted that the rhetoric of CALL had gone ahead of the reality: promises of a revolution in language learning have not come to pass. Ben Shneiderman uttered the wise words, "computers are no more intelligent than a wooden pencil" and "the sound of education is the buss of students talking together".

These general cautions expressed by the experts are proved again and again by researchers' study. Rosamund Sutherland et al (2000) conducted a case study to find out how young people engage with computer at home. It shows that the home computer is used primarily as a game machine. Is the computer in school viewed in a like manner? Then, the role of teacher in CALL in significant. Computer requires the guiding hand of a human being. What the computer offers learners is not "free standing", and the human teacher's role is undiminished. Levy (1997) undertook a comprehensive survey of experienced CALL practitioners to determine how they conceptualized and used the medium. On common response among the 104 participants in the survey identified an approach to CALL based on learners' needs and the curriculum, rather than on the computer itself. Many respondents claimed to set their students CALL activities in the context of the same communicative approach that they would adopt in the conventional classroom, insisting, for example, on the authentic content of exercises, problem solving, and oral participation.

It is possible that most learners, too, would affirm that CALL activities should be associated with a teaching program. A case study was conducted by Felix (1997) to evaluate a CD-ROM program called Theater Interactive, which she herself developed. What is interesting in the context of the question of whether the computer is best used as a tool or a tutor is that $75.5 \%$ of the 37 subjects wanted 
to regard the program as a complement to classroom instruction, and not as a stand-alone task for self-access use. Further more, it is noteworthy that these students were of advanced level, and might have been expected to manner, or sought to manage, their learning more independently.

In classroom, teachers' role is proved to be strong. Then what about their role in Internet projects? Computer mediated communication on the Internet is undertaken between individuals or groups who may be separated by meters or by continents. The communication may be either asynchronous, in the form of e-mail, where a reply to a message can be received any time after it has been sent, or synchronous, in the form of electronic discussion or simulation, where messages sent by one person are replied to immediately by others who are on-line at the same time. Projects base on computer learning networks have been under taken for some years, and the benefits are becoming evident. Warschauer et al. (1996) for example, list the potential benefits for the learner under the headings of autonomy, equality, and critical learning skills.

For the argument of this paper, the significant point is that, in network projects, the teacher's role remains strong. In the case of e-mail, Warschauer (1995, cited in Levy 1997) lists a number of tasks for teachers: choosing software, mastering the e-mail system, training students, arranging access to computers, designing handouts and instructions, assisting students in the early stages, preparing task-based projects, monitoring progress, and offering continuing guidance. To these duties would be added the special responsibility to ensure that a certain decorum be maintained in the exchanges over the network, the teacher has to intervene if discussions become heated, or misunderstandings arise. The teacher will also have to be alert to the natural reluctance of some learners to talk openly about themselves to a stranger, as computer conferencing often obliges one to do.

\section{THE FACILITATING ROLE OF THE COMPUTER IN CALL}

From the studies above, it is easy for us to draw such a conclusion: the computer's role in education is that of a medium. Far from threatening the teacher's position, it is totally dependent on the teacher in many ways; for example, it is unable to create educational materials without a human to detect it. The teacher must specify all the linguistic material and instructions for its presentation. It is the teacher, then, who can make the computer assume various roles. Whatsoever, the computer's role in language learning is undeniable, though at the same time, it is constrained to limited areas, just as mentioned above. We should not neglect its distinguish strength. On the contrary, we should give it a thorough understanding with positive attitude. Let's take a serious look at the advantages of the computer in language learning.

The computer can handle a much wider range of activities, and much more powerfully, than other technological aids, the television, the radio, or any other electronic invention.

From the point if view of the teacher, the computer presents several aspects of particular promise. Prominent among these is its versatility in handling different kinds of material. The simplest is the one-way presentation of information, in the form of text, graphics, audio and video. The computer can also handle question-and-answer routines, simulated "dialogues", hypotheses testing, and many other types of exercise. It can choose questions in sequence or at random from the list of questions supplied by the teacher. It can "branch" to different parts of the package, depending on many different factors, and can do so at any point: when the student has completed the session, the computer can record results, errors, success rates, the time spent, and much more information for the teacher to view at later time. As a result of this in formation, or from the reactions of the students, the teacher is able to revise and refine the material at any stage. The entire process does not need the teacher to be in direct contact with the students although we have found that CALL works best when integrated with normal classroom teaching patterns.

All these factors have the effect of freeing the teacher from some constraints imposed by heavy teaching schedules. And this is particularly the case of the computer is handling drill and revision sessions, to which it is well suited. This will make more time available for creative and imaginative teaching in those parts of the course where teacher-student contact is more necessary.

For the student too, the computer offers many advantages. First among these is access. The computer's flexibility of time allows the student the choice of when to study them. This factor makes many educational courses available to those who have no chance to take them. More than this, the computer can also allow students to take courses, or parts of course, at a distance. Distance teaching is eminently feasible by computer. Whatever the factors of time and distance, the computer retains its potential for personalized instruction. The branching capacity which we have already mentioned means that the computer can be made sensitive to the learner's pace, pattern of responses, and so on, and can adjust the linguistic material to the needs of the individual.

The learning session can also be more concentrated than normal class sessions. The student has the exclusive attention of the computer. There is no "low attention" period as the student waits for his or her turn to come around in class. For all practical purpose, each student has the computer's full attention and can work at the speed best suited to the individual. Each student response receives a reply from the computer, virtually instantaneously, with appropriate feedback in the form of comments, assessment and guidance.

\section{CONCLUSION}

From the set of affairs described above, an important 
implication can be drawn, if the administrators wish to exploit the rich potential of CALL. That is, they must recognize that students can only learn from computers with the instruction and supervision of teachers. CALL will not be effective without this essential interaction of teachers and students. Additionally, the feeling of teachers about computer should be concerned with. Most language teachers are not comfortable with high technology. Because of unlike so many of their students, they have not grown up with computers. Some may fear that administrators will use computers to replace them (Evans 1998); others may resent the administrators' decision to spend large sums of money on high technology rather than on other matters just as books, classroom furniture, and people. Only then, the computer can be put into full use in facilitating the language learning process.

\section{REFERENCE}

[1] Warschauer, M. Kern, R. (2000). Networked-based language teaching: Concepts and practice. New York: Cambridge University Press.

[2] Ling, Ningjian (2003). Contemporary Cognitive Psychology. Beijing: Shanghai Education Press

[3] Kern, R.\&Warschauer, M. 2000. "Theory and Practice of Network-based language teaching”. In M. Warschauer\& R. Kern (eds.), Network-based Language Teaching: Concepts and Practice. New York: Cambridge University Press.

[4] Healey, D. \& Johnson, N. (Ed.). (1995). 1995 TESOL CALL interest section software list. Alexandria, VA: TESOL Publications.

[5] Ravinder Koul,Laura Roy,Sittichai Kaewkuekool,Suthee Ploisawaschai. Multiple goal orientations and foreign language anxiety[J]. System . 2009 (4)

[6] Tanja Bipp,Ricarda Steinmayr,Birgit Spinath. Personality and achievement motivation: Relationship among Big Five domain and facet scales, achievement goals, and intelligence[J]. Personality and Individual Differences. 2008 (7) 